\title{
PENGARUH KESIAPAN MENTAL TERHADAP HASIL UJIAN PROGRAM KESETARAAN
}

\section{Bayu Adi Laksono}

STKIP Modern Ngawi, bayuadi@ stkipmodernngawi.ac.id Jl. Ir. Soekarno No. 9 Grudo Ngawi

\begin{abstract}
Abstrak
Penelitian ini bertujuan untuk mengetahui pengaruh kesiapan mental terhadap ujian program kesetaraan. Penelitian ini dilakukan di Pusat Kegiatan Belajar Masyarakat (PKBM) yang berada di Kediri yakni PKBM Pagut, PKBM ALMadinah, dan PKBM Ar-Rahman. Penelitian ini memakai pendekatan kuantitatif dengan analisis regresi linier berganda serta memanfaatkan aplikasi SPSS 24. Teknik sampling menggunakan cluster random sampling dan penghitungan banyaknya sampel menggunakan rumus slovin sehingga diperoleh sebanyak 120 warga belajar sebagai sampel penelitian. Hasil penelitian menunjukkan kesiapan mental berpengaruh sebesar 58,6\% terhadap hasil ujian program kesetaraan dan Nilai korelasi berganda (R) sebesar 0,772 menunjukkan hubungan yang sangat kuat antara nilai variabel bebas dan terikat. Hal tersebut menunjukkan bahwa pengelola lembaga maupun warga belajar harus memiliki kondisi mental yang baik agar hasil ujian mendapatkan dampak yang positif.

Kata Kunci: Kesiapan mental, ujian, kesetaraan
\end{abstract}

\section{PENDAHULUAN}

Data mengenai angka putus sekolah siswa SMA maupun SMK yang ada di daerah Kediri dan daerah sekitarnya menunjukkan angka yang cukup mengejutkan. Tercatat sepanjang tahun 2017/2018 di Kabupaten Kediri terdapat 163 siswa jenjang SMA yang harus putus sekolah. Daerah di sekitar Kabupaten Kediri, seperti Kabupaten Nganjuk, Kabupaten Tulungagung serta Kota Kediri juga cukup mengejutkan. Di Kabupaten Nganjuk setidaknya ada 84 siswa SMA yang putus sekolah, disusul Kabupaten Tulungagung berjumlah 50 siswa serta di Kota Kediri tercatat 71 siswa. Begitupun di jenjang SMK, data di Kementerian Pendidikan dan Kebudayaan Republik Indonesia mencatat sebanyak 355 siswa
SMK putus sekolah di Kabupaten Kediri, di Kota Kediri setidaknya ada 275 siswa SMK yang putus sekolah. Sedangkan di Kabupaten Nganjuk 382 siswa dan Kabupaten Tulungagung sebanyak 205 siswa. (Kementerian Pendidikan dan Kebudayaan, 2018).

Dunia pekerjaan menuntut para pekerjanya memiliki keterampilan yang sejalan dengan apa yang dibutuhkan oleh perusahaan. Kemampuan dan keterampilan salah satunya diukur dengan jenjang pendidikan yang telah ditempuh. Semakin tinggi jenjang pendidikan yang dilalui, semakin tinggi pula potensi pekerjaan layak yang akan mereka terima. Meskipun di era keterbukaan dan akses yang tidak terbatas seperti ini, keterampilan dan kemampuan tidak hanya diukur dari ijazah, namun 
nampaknya dunia kerja masih menjadikan ijazah sebagai salah satu indikator dan persyaratan administrasi untuk merekrut pekerja. Pandangan perusahaan mengenai indikator jenjang pendidikan sebagai salah satu syarat untuk merekrut karyawan tentunya memiliki pertimbangan. Hasil penelitian menyatakan bahwa pendidikan dipercaya dapat meningkatkan produktivitas pekerja serta dapat menjadikan pekerja lebih menguasai produk-produk yang ada pada perusahaan dan mampu menjadi motivasi bagi pekerja lainnya dalam melakukan pendidikan dan pencapaian target kerja (DEHOTMAN, 2016). Hal tersebut tentunya memperkuat argumen bahwa rekrutmen pekerja dengan mensyaratkan jenjang pendidikan bukanlah hal yang tanpa pertimbangan.

Tantangan dan hambatan bahwa angkat putus sekolah yang cenderung tinggi sedangkan dunia kerja mensyaratkan jenjang pendidikan sebagai salah satu syarat administrasinya. Pendidikan formal (sekolah) tidak memberikan akses kepada masyarakat yang berkeinginan untuk meningkatkan jenjang pendidikannya namun terbatas pada usia yang tidak lagi usia sekolah. Keterbatasan dalam mengakses pendidikan tersebut menjadi potensi jalur pendidikan nonformal berperan sebagai suplemen, komplemen dan subtitusi pendidikan formal. UndangUndang Nomor 20 Tahun 2003 mengenai sistem pendidikan nasional, menyatakan bahwa pendidikan nonformal adalah jalur pendidikan di luar pendidikan formal yang dapat dilaksanakan secara terstruktur dan berjenjang (pasal 1 ayat 12). Pendidikan nonformal diselenggarakan bagi warga masyarakat yang memerlukan layanan pendidikan yang berfungsi sebagai pengganti, penambah, dan/atau pelengkap pendidikan formal dalam rangka mendukung pendidikan sepanjang hayat (Pasal 26 ayat 1). Pendidikan nonformal meliputi pendidikan kecakapan hidup, pendidikan anak usia dini, pendidikan kepemudaan, pendidikan pemberdayaan perempuan, pendidikan keaksaraan, pendidikan keterampilan dan pelatihan kerja, pendidikan kesetaraan, serta pendidikan lain yang ditujukan untuk mengembangkan kemampuan peserta didik (Pasal 26 ayat 3). Contoh program pendidikan nonformal yang memberikan akses penuh terhadap masyarakat yang ingin meningkatkan jenjang pendidikan namun terhalang usia adalah pendidikan kesetaraan. Pendidikan kesetaraan memberikan layanan pendidikan paket $\mathrm{A}$, paket $\mathrm{B}$ dan paket $\mathrm{C}$ yang setara dengan SD, SMP, SMA,SMK/Sederajat.

Seperti selayaknya program pendidikan pada umumya, pendidikan kesetaraan tentunya membutuhkan evaluasi untuk mengukur seberapa paham warga belajar mampu menyerap materi yang disampaikan oleh tutor. Penyelenggara program pendidikan kesetaraan memberikan evaluasi secara berkala pada warga belajarnya. Salah satu evaluasi yang dilakukan adalah ujian akhir sekolah. Ujian akhir sekolah dan ujian nasional berbasis komputer merupakan alat evaluasi program kesetaraan yang memberikan gambaran capaian kemampuan akademik warga belajar di akhir program. Ujian akhir sekolah memiliki suasana yang cenderung menegangkan karena merupakan evaluasi terakhir bagi warga belajar. Dalam menyongsong ujian akhir sekolah tentunya terdapat persiapan-persiapan yang dilakukan warga belajar agar mendapatkan nilai yang sesuai dengan kemampuan yang mereka miliki. Sebagai masyarakat 
Indonesia pada umumnya yang menjunjung nilai-nilai religius begitu tinggi, tentunya warga belajar salah satunya mempersiapkan diri dari segi mental spriritual. Berdasarkan penelitian terdahulu terdapat pengaruh yang signifikan antara kesehatan mental dengan hasil belajar dimana peserta didik yang memiliki kesehataan mental yang stabil dalam proses pembelajaran maka berpotensi dapat meningkat hasil belajarnya (Fatimah, 2019). Kesehatan mental adalah keharmonisan yang kuat antara fungsi jiwa dan memiliki kemampuan dalam mengelola masalah yang terjadi dan memandang secara positif kebahagian dan kemampuan dirinya. Fungsi jiwa yang dimaksud adalah pikiran, perasaan, sikap jiwa, pandangan dan keyakinan hidup, harus dapat membantu satu sama lain, sehingga dapat menjauhkan orang lain dari perasaan ragu dan bimbang (Daradjat, 2016). Berdasarkan kajian tersebut paling tidak terdapat tiga indikator yang menyatakan bahwa seseorang siap dan sehat secara mental yakni dimensi spiritual, dimensi psikologis serta dimensi sosial. Ketiga dimensi tersebut yang menjadi variabel dalam penelitian ini. Peneliti berkeingian untuk mengukur sejauh mana pengaruh kesiapan mental terhadap hasil ujian program kesetaraan, dalam hal ini adalah paket $\mathrm{c}$ setara SMA/Sederajat. Hasil ujian diukur berdasarkan hasil ujian akhir sekolah yang dilaksanakan masing-masing penyelenggara program. Peneliti berharap hasil penelitian ini mampu memberikan gambaran penyelenggara program keaksaraan untuk memberikan persiapan sebelum ujian sekolah, baik persiapan akademis maupun spiritual.

\section{METODE}

Penelitian ini memakai pendekatan kuantitatif, serta teknik analisis datanya menggunakan analisis regresi linier berganda dengan menggunakan SPSS 24. Penelitian ini dilaksanakan pada penyelenggara program kesetaraan paket c di Kota Kediri yang sedang melaksanakan ujian sekolah, yakni PKBM AL-Madinah, PKBM Ar-Rahman, PKBM Pagut. Sebagai variabel bebas pertama adalah dimensi spiritual (X1), variabel bebas kedua adalah dimensi psikologis (X2), dan sebagai variabel bebas ketiga adalah dimensi sosial (X3). Sebagai variabel terikat adalah hasil belajar berupa nilai ujian kesetaraan paket $\mathrm{c}$ (Y). Seluruh peserta program keseteraan paket c yang mengikuti ujian sebanyak 170 warga belajar. Menggunakan cluster random sampling dengan penentuan jumlah sampel menggunakan rumus slovin dengan margin of error 5\%, sehingga di peroleh sampel sebanyak 120 warga belajar.

$$
\begin{aligned}
& \mathrm{n}=\mathrm{N} /\left(1+\left(\mathrm{Nx} \mathrm{e}^{2}\right)\right) \\
& \mathrm{n}=170 /\left(1+\left(170 \times 0,05^{2}\right)\right) \\
& \mathrm{n}=170 /(1+(0,425) \\
& \mathrm{n}=170 / 1,425 \\
& \mathrm{n}=119,298 \\
& \mathrm{n}=120
\end{aligned}
$$

\begin{tabular}{lccc}
\hline Nama PKBM & $\mathrm{N}$ & $\%$ & $\mathrm{n}$ \\
\hline PKBM AL-Madinah & 85 & $50 \%$ & 60 \\
\hline PKBM Ar-Rahman & 51 & $30 \%$ & 36 \\
\hline PKBM Pagut & 34 & $20 \%$ & 24 \\
\hline \multicolumn{2}{c}{ Total Sampel } & & 120 \\
\hline
\end{tabular}

Penelitian menggunakan angket sebagai instrumen pengumpul data. Uji validitas dan reliabilitas instrumen menggunakan warga belajar kesetaraan paket $\mathrm{c}$ di tempat lain. Instrumen dinyatakan valid dengan semua koefisien $>0,3(\mathrm{r}=0,360-0,790)$ dan dinyatakan reliabel dengan nilai alpha 0,869 . 


\section{HASIL DAN PEMBAHASAN}

Penelitian ini melibatkan 120 warga belajar program kesetaraan dimana $52,5 \%$ adalah laki-laki dan $47,5 \%$ diantaranya adalah perempuan dari tiga PKBM (Pusat Kegiata Belajar Masyarakat). Rata-rata hasil ujian program kesetaraan tergolong pada angka yang sangat tinggi yakni pada kisaran angka 81,22

Dalam penelitian ini sebelum mengarah pada analisis data, peneliti terlebih dahulu menggunakan uji asumsi klasik, yakni uji asumsi normalitas, uji asumsi heteroskedastisitas, dan uji asumsi multikolinieritas. Penelitian ini menggunakan metode probability plot sebagai uji asumsi normalitas.

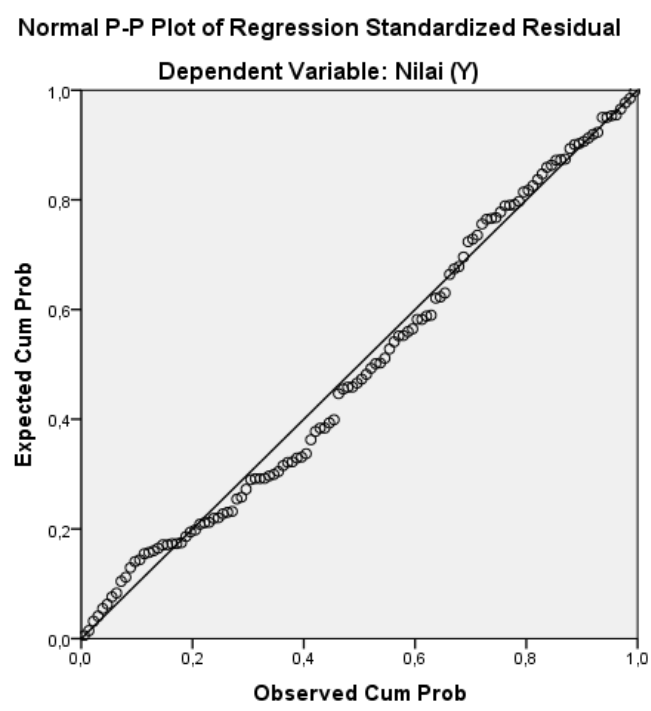

Gambar di atas menunjukkan bahwa titiktitik residual cenderung untuk menyebar di antara garis diagonal. Hal tersebut menyatakan bahwa residual dinyatakan menyebar secara normal.

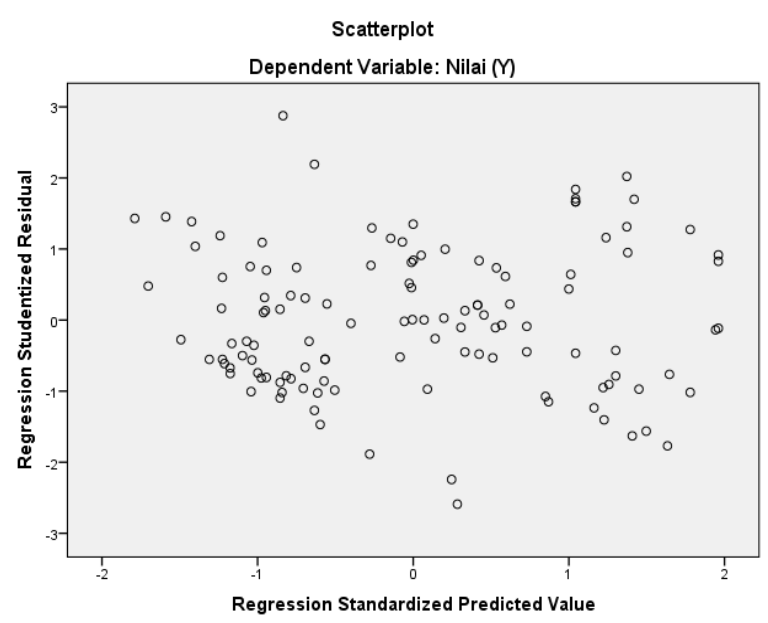

Uji asumsi selanjutnya adalah uji asumsi heteroskedastisitas yang bertujuan untuk mengetahui varian variabel yang tidak kostan. Dalam penelitian ini uji asumsi heteroskedastisitas menggunakan metode scatter plot. Gambar di atar menunjukkan bahwa titik-titik residual menyebar secara acak, dengan demikian residual dinyatakan menyebar secara normal.

\begin{tabular}{lcc}
\hline & Tolerance & VIF \\
\hline (Constant) & & \\
\hline Spiritual &, 619 & 1,616 \\
\hline Psikologis &, 568 & 1,761 \\
\hline Sosial &, 452 & 2,213 \\
\hline
\end{tabular}

Uji asumsi selanjutnya adalah uji asumsi multikolinieritas dimana dalam uji di atas menyatakan bahwa nilai Variance Inflation Factor dari tiga variabel tersebut menyatakan angka di atas 10 .

\section{Analisis Data}

\begin{tabular}{cccc}
\hline Model & R & R Square & Adj R Square \\
\hline 1 &, $772^{\mathrm{a}}$ &, 596 &, 586 \\
\hline
\end{tabular}

Nilai Adj Aquare (R2) sebesar $0,586(58,6 \%)$ yang berarti besarnya variabel hasil ujian program kesetaraan (Y) yang dapat dijelaskan oleh variabel dimensi spiritual (X1), dimensi psikologis (X2), dan dimensi sosial (X3) sebesar 58,6\%. Artinya 
besaran kontribusi variabel dimensi spiritual (X1), dimensi psikologis (X2), dan dimensi sosial (X3) terhadap hasil ujian program kesetaraan (Y) sebesar 58,6\%, sedangkan sisanya sebesar $41,4 \%$ merupakan kontribusi variabel lain yang tidak termasuk dalam penelitian. Nilai korelasi berganda (R) sebesar 0,772 menunjukkan hubungan yang sangat kuat antara nilai variabel kontribusi dimensi spiritual (X1), dimensi psikologis (X2), dan dimensi sosial (X3) secara menyeluruh dengan variabel hasil ujian program kesetaraan (Y).

\begin{tabular}{lccc}
\hline \multicolumn{1}{c}{ Model } & $\begin{array}{c}\text { Mean } \\
\text { Square }\end{array}$ & F & Sig. \\
\hline Regression & 366,096 & 57,086 &, $000^{b}$ \\
\hline Residual & 6,413 & & \\
\hline Total & & & \\
\hline
\end{tabular}

Hasil perhitungan di atas menunjukkan statistik uji Fhitung sebesar 57,086 dengan probabilitas sebesar 0,000 , sedangkan nilai alpha sebesar $0,05 \quad(5 \%)$. Hal ini menunjukkan bahwa nilai probabilitas < alpha, sehingga H0 ditolak. Dengan demikian dapat dinyatakan bahwa terdapat pengaruh yang signifikan secara simultan variabel dimensi spiritual (X1), dimensi psikologis (X2), dan dimensi sosial (X3) terhadap hasil ujian program kesetaraan (Y).

\section{Program Kesetaraan}

Program kesetaraan merupakan program yang digagas oleh pemerintah yang bertujuan untuk meningkatkan partisipasi pendidikan masyarakat baik dalam usia sekolah maupun di luar usia sekolah. Pendidikan kesetaraan cenderung lebih fleksibel dari segi waktu dan konten pembelajaran sehingga agaknya lebih disukai oleh masyarakat yang memiliki kebutuhan belajar namun memiliki keterbatasan dalam hal waktu. Program pendidikan kesetaraan merupakan salah satu jenis dari pendidikan nonformal yang bersifat sebagai suplemen, komplemen, maupun subtitusi pendidikan lainnya. Dalam prakteknya pendidikan kesetaraan seringkali menjadi penyelamat bagi orangorang yang membutuhkan pengakuan jenjang pendidikan yang digunakan untuk urusan pekerjaan, jabatan, maupun urusan lain yang berkaitan dengan ijazah.

Studi pendahuluan menunjukkan bahwa angka putus sekolah pada jenjang sekolah menengah di wilayah Kediri dan sekitarnya menunjukkan angka cukup tinggi. Hal tersebut merupakan potensi dari penyelenggaraan pendidikan kesetaraan secara maksimal. Hal tersebut tercermin dari banyaknya lembaga pendidikan nonformal yang menyelenggarakan program kesetaraan. Meskipun memiliki potensi yang cukup besar untuk berkembang, penyelenggaraan lembaga pendidikan nonformal harus memiliki mekanisme yang terukur karena hasil riset menyebutkan bahwa kinerja pendidikan kesetaraan memiliki nilai 69,05 yang bermakna bahwa capainnya kurang dari 70\% (Hermawan, 2012). Termasuk di dalamnya adalah memberikan dorongan kepada warga belajar untuk senantiasa memiliki kesehatan mental yang bagus

\section{Kesiapan Mental Pada Ujian Kesetaraan}

Hasil analisis data yang dilakukan menunjukkan bahwa kesiapan mental berpengaruh sebesar 58,6\% terhadap hasil ujian program kesetaraan. Hal tersebut menunjukkan bahwa semakin siap dari segi mental warga belajar dalam menghadapi ujian kesetaraan semakin tinggi pula hasil atau nilai yang didapatkan. Hasil analisis 
lainnya menunjukkan bahwa nilai korelasi berganda sebesar 0,772 yang menunjukkan kuatnya hubungan antara kesiapan mental dengan hasil ujian program kesetaraan. Hal tersebut memperkuat kajian yang menyatakan bahwa kesiapan belajar memberi pengaruh yang positif dan signifikan terhadap hasil belajar (Saifullah, 2014). Seseorang yang telah siap dengan materi yang dipelajari akan cenderung tenang dan percaya diri dalam menghadapi ujian

\section{PENUTUP}

Kesiapan mental berpengaruh sebesar $58,6 \%$ terhadap hasil ujian program kesetaraan, semakin siap dari segi mental warga belajar dalam menghadapi ujian kesetaraan semakin tinggi pula hasil atau nilai yang didapatkan serta hubungan antara kesiapan mental dengan hasil ujian program kesetaraan menunjukkan nilai yang sangat kuat.

Saran yang dapat diberikan berdasarkan hasil penelitian ini adalah hendaknya setiap lembaga memiliki unit konseling yang memberikan pendampingan secara mental bagi warga belajar yang akan mengikuti ujian, serta bagi warga belajar hendaknya memiliki bekal materi yang cukup agar tidak timbul rasa bimbang dan khawatir sebelum menghadapi ujian program kesetaraan.

\section{DAFTAR PUSTAKA}

Daradjat, Z. (2016). Kesehatan Mental. PT Gunung Agung.

DEHOTMAN, K. (2016). Pengaruh pendidikan terhadap kinerja karyawan. Jebi (Jurnal Ekonomi Dan Bisnis Islam), 1(2), 217-234. http://journal.febi.uinib.ac.id/index.ph p/jebi/article/view/36

Fatimah, F. (2019). PENGARUH KESEHATAN MENTAL TERHADAP HASIL BELAJAR PENDIDIKAN AGAMA ISLAM DI SMP PIRI JATI $A G U N G$ [UIN Raden Intan Lampung]. http://repository.radenintan.ac.id/7052 /1/SKRIPSI FATIMAH.pdf

Hermawan, I. K. D. (2012). the Performance of Equality Education As a Type of Non Formal. Jurnal Pendidikan Dan Kebudayaan, 18(September 2011), 65-84.

Kementerian Pendidikan dan Kebudayaan. (2018). Ikhtisar Data Pendidikan dan Kebudayaan tahun 2017/2018. http://publikasi.data.kemdikbud.go.id/ uploadDir/isi_4B619F17-97F5-4B93BB0B-7F83B5512B0B_.pdf

Saifullah, A. M. (2014). Pengaruh kesiapan belajar terhadap hasil belajar matematika pokok bahasan limit pada peserta didik kelas XI semester 2 di Madrasah Aliyah Matholi'ul Huda Bugel Jepara tahun pelajaran 2012/2013. IAIN Walisongo. 